\title{
Histopathology of papilloma virus infection of the cervix uteri : the history, taxonomy, nomenclature and reporting of koilocytic dysplasias
}

\author{
STEWART FLETCHER
}

From the Department of Pathology, University Medical School, Teviot Place, Edinburgh EH8 $9 A G$

SUMMARY Papilloma virus infections of the squamous cervix are common and determine the incidence of koilocytes in cervical smears and biopsies.

Typical exophytic condyloma acuminatum accounts for few of the infections. Most are "flat condylomata" (flat koilocytosis)-slightly raised plaques of flat profile. Superficial koilocytosis, dyskeratosis and often disturbed deep cells are their main histological features.

The association between koilocytosis and dysplasia is considered and the different taxonomic approaches to the koilodysplastic states are compared. Equivalence is established between different nomenclatures by reference to the familiar dysplastic grades. Methods of reporting koilodysplasias are given and a prognostically difficult state of "full thickness" or "plenary" koilocytosis is described.

In applying the "high technology" of nucleic acid hybridisation to confirm the lesion specificity of papilloma virus strains the lesions must be well defined and clearly identified by precise nomenclature: the nature and nomenclature of the lesions is critically discussed.

The past six years have seen a rising interest in the wart virus infections of the cervix and especially in their possible connection with cervical malignancy. Accordingly, pathologists are now being asked to report not merely the presence of wart virus lesions but their significance for patient care.

Here the development of the subject is traced and the morphology and nomenclature of the koilocytic states described. The taxonomic problems created by the need to integrate koilocytic and dysplastic states into a simple safe scheme are detailed.

\section{Wart virus infections of the cervix: history of their recognition}

In 1976 Meisels and Fortin ${ }^{1}$ in reviewing the exfoliative cytology of the viral wart condyloma acuminatum wrote "no clear cytological pattern has as yet been identified which would permit the unequivocal identification of condyloma acuminatum from the cellular sample." They attempted to remedy the state by publishing a correlation between the known cytological appearances of condyloma acuminatum and whatever visible lesions of

Accepted for publication 25 Novembcr 1982 the vagina and cervix could be found at colposcopy and selective biopsy.

The cytological description includes dyskeratotic cells, bi- or multinucleate cells and a cell, already well known, which Meisels and Fortin called "balloon cells" (Fig. 3). The characteristic of the balloon cells was a prominent perinuclear clearing or "halo" which failed to stain with eosin or periodic acidSchiff (PAS). Similar cells had been found before in vaginal smears from pregnant and non-pregnant women by Papanicolaou who described them in $1933 .^{2}$ He noted their uncertain significance and declared that their "topographic origin is not always clear." In 1949 similar cells were described by Ayre ${ }^{3}$ who called them "halo cells" and by Koss and Durfee ${ }^{4}$ who called them koilocytes ("empty cells"), still without knowledge of what they were. However, the 1960 supplement to Papanicolaou's Atlas ${ }^{5}$ firmly associates, for the first time, the halo cells with condyloma acuminatum. Shortly after, Naib and Masukawa ${ }^{6}$ also traced exfoliated koilocytes to the superficial layers of cervical condyloma acuminatum. In 1968 Dunn and Ogilvie ${ }^{7}$ confirmed some earlier work by showing virus in the nuclei of stratum intermedium cells of condyloma acuminatum. They added that the virus-infected cell 


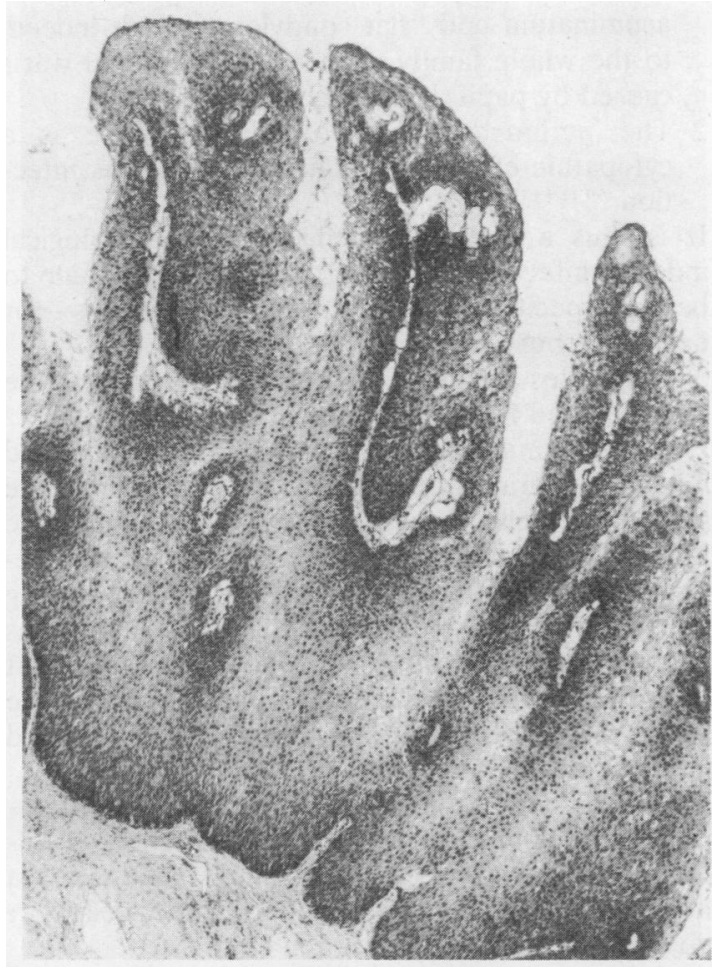

Fig. 1 Condyloma acuminatum. The exophytic lesion (Kondulos: a knuckle) is well-named. The individual processes have connective tissue cores and some are of tapering (acuminate) profile. Koilocytes (Fig. 3), not visible at this magnification, are scattered among the superficial keratinising squames. Haematoxylin and eosin $\times 160$.

had "an unusually wide perinuclear zone free from cytoplasmic organelles." The reason for the perinuclear halo was thus discovered without calling the infected cells by any of their familiar names. It is now accepted that the perinuclear halo which characterises the koilocyte is a cytopathic effect of papilloma virus infection.

Meisels and Fortin's description ${ }^{1}$ of the cytology added little to the existing cytological criteria of condyloma acuminatum ${ }^{6}$ but their observations on the precise nature of the accompanying lesions proved interesting. About $2 \%$ of the adult female population exfoliated koilocytes, but only a tiny proportion bore the expected condyloma acuminatum at colposcopy and confirmatory biopsy (Fig. 1).

The majority had a different lesion probably previously undescribed (Fig. 2). It shared the intraepithelial characteristics of condyloma acuminatum, including superficial koilocytes, but lacked the exophytic, corrugated, secondary fea-

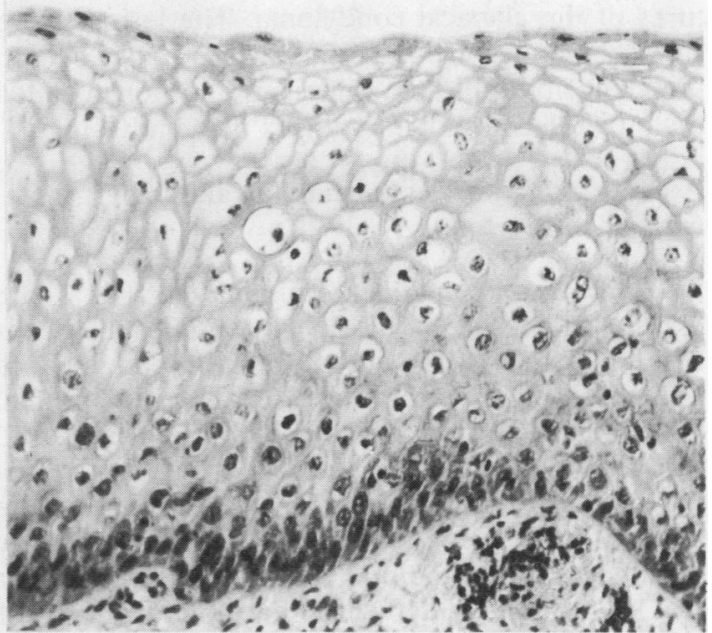

Fig. 2 "Flat condyloma" (flat koilocytosis). Part of a slightly-raised whitish plaque. Note the absence of basal cell dysplasia in this example. Large numbers of round vacuolated koilocytes are present in the upper strata (see Fig. 3). Haematoxylin and eosin $\times 160$.



Fig. 3 Koilocytes $\rightarrow$ the common characterising cells of condyloma acuminatum and flat condyloma. They are abnormally spheroidal and the perinuclear halo is a striking cytopathic effect of the virus made more distinct by a narow peripheral cytoplasmic condensation. Haematoxylin and eosin $\times 500$. 
tures of the classical condyloma. The lesions were shallow plaques with a surface which might be flat, undulant or cobblestone. Meisels and Fortin called them by the contradictory term "flat condylomata."

\section{Anatomical features of acuminate and "flat" condylomata}

The features of condyloma acuminatum (Fig. 1) are excellently recalled by its terminology. "Condyloma" stems from the Greek "kondulos" (a knuckle)-the expanded, exophytic profile. "Acuminatum" stems from the Latin "acuminare" (to make pointed)-the tapering profile of its processes. American writers sometimes refer to the rough surface processes as "asperities." Clearly "condyloma acuminatum" should be reserved for that lesion alone both by propriety and by priority of application.

In the "flat condyloma" of Meisels and Fortin" any marked exophytic tendency or digitation is absent (Fig. 2). Microscopically, there are superficial koilocytic cells accompanied by occasional dyskeratotic cells. In the variety originally described by Meisels et al, ${ }^{8}$ the deeper cells are orderly and show only a little basal cell hyperplasia, perhaps with an occasional double nucleus-that is, dysplastic changes in condyloma acuminatum and, at least in some "flat condylomata" are minimal. Flat lesions, however, are much more often accompanied by dysplasia than condyloma acuminatum.

Meisels et al, ${ }^{8}$ also claim the existence of another form of condyloma of "endophytic" nature "with pseudoinvasive aspects." Inspection of the example in their Figs. 27 and 28 show the "endophytic" processes to be nothing more than koilocytosis in a branching, epidermidised gland.

\section{Behaviour of "fiat condylomata": importance of the koilocyte}

Meisels $e t a^{8}$ thought flat condyloma were precursors of condyloma acuminatum. It is now believed that very few flat lesions are in progress to condyloma acuminatum. ${ }^{9}$ It is, therefore, likely that condyloma acuminatum and "flat condylomata" are distinct lesions in their associations and behaviour. Further, high stringency DNA hybridisation ${ }^{10}$ has shown that the HPV-6 strain of virus which causes condyloma acuminatum could be found in only two of six flat condylomata: lack of hybridisation in the remainder was thought to be due either to its absence or to infection with a different strain.

\section{Significance of koilocytosis}

1 Koilocytosis is common to condyloma acuminatum and "flat condyloma" and, indeed, to the whole family of human and animal warts caused by papilloma virus strains.

2 The perinuclear halo of the koilocyte is a cytopathic effect of productive wart virus infection. ${ }^{7911-13}$

It is thus a reasonably reliable histopathological index of infection although some believe the halo to be non-specific ${ }^{14}$ or due to other infections-for example, trichomonas. ${ }^{15}$

3 Koilocytes are degenerating cells destined to die or be shed from the epithelium.

Even in normal squamous epithelium of skin $^{16}$ and mucus membranes ${ }^{17}$ there is good evidence that the superficial cells (where koilocytes appear) are involuting and will die or be shed. Wart virus infection accelerates the death of its target cells among the dehiscing squames. The lethal cellular effect is confirmed by the arrays of virions which spread out from the nucleus to fill the cytoplasm ${ }^{13}$ and by the well known lytic mode of release of the naked icosahedral DNA viruses. ${ }^{18}$

Thus superficial squamous cells die, either naturally, or prematurely by wart virus infection. It follows that koilocytes cannot themselves generate a malignant cell line although other, deeper cells may do so.

4 Koilocytes (wart virus infection) are commonly associated with dysplasia and the connection may be causal.

5 Koilocytosis creates problems of taxonomy, nomenclature and reporting due to the need to integrate koilocytosis into the familiar dysplastic grades.

The last two associations of koilocytes are considered more fully below.

\section{Papilloma virus infection, koilocytes and cervical malignancy}

Some infective warts can transform from benign to malignant states: the rare human genodermatosis epidermodysplasia verruciformis does so under the influence of light ${ }^{19}$ and bovine oesophageal papilloma under the influence of bracken fern. ${ }^{20}$.

In 1977 Meisels, Fortin and Roy, ${ }^{8}$ impressed by reports $^{21-23}$ that condyloma acuminatum could undergo malignant change postulated that "flat condylomata" could behave likewise. They regarded the "fiat condyloma" as an early stage in the development of condyloma acuminatum. They also considered both forms to be a "step in the direction of malignancy" and published a hypothetical chain of causation of the dysplastic states which ran: (i) condyloma acuminatum; (ii) mild and moderate dysplasia; (iii) severe dysplasia and carcinoma-in- 


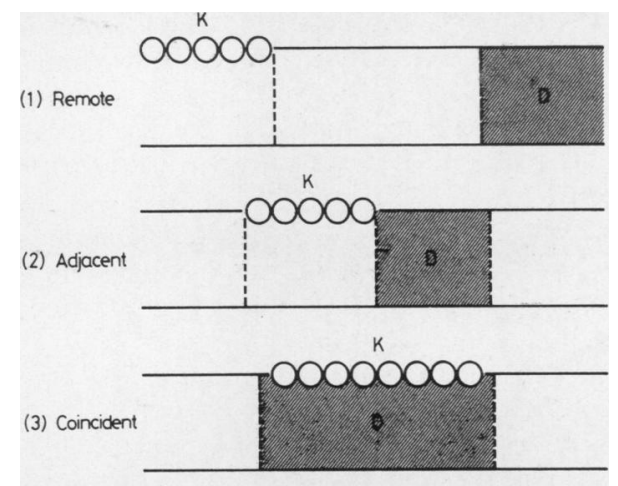

Fig. 4 Association between koilocytosis (K) and dysplasia (D).

situ; and (iv) invasive squamous carcinoma. A very full list of references to malignant transformation can be found in a recent review by Meisels' group. ${ }^{24}$

\section{ASSOCIATION OF FLAT KOILOCYTOSIS AND \\ DYSPLASIA}

Published reports92526 and common experience confirm that "flat" koilocytosis can be found frequently along with "disturbed squamous epithelial cells indistinguishable histologically from dysplasia." Before koilocytosis was recognised as a viral cytopathic effect such "disturbances" were regarded unquestionably as dysplastic-a view still necessary for safe patient care. However, they are not necessarily dysplastic. Some might be prekoilocytic cytopathic effects of the virus devoid of dysplastic behaviour. A speculative analysis of the different possible cell-virus interactions is in preparation. ${ }^{27}$

In practice, koilocytosis and presumptive dysplasia, even in small biopsies can be associated (and reported) in the three ways shown in Fig. 4.

\section{FUTURE BEHAVIOUR OF FLAT KOILOCYTOSIS}

Flat condylomata without dysplasia persist unchanged for months after which $60 \%$ regress. $^{28}$ The remainder progress:

(a) without change of character-by spreading.

(b) with change of character:

(i) to condyloma acuminatum (rare). ${ }^{9}$

(ii) possibly to dysplasia and carcinoma-in-situ.

Taxonomy, nomenclature and reporting of koilocytosis and dysplasia

THE AUTHOR'S SYSTEM: DYSPLASIA BASED After studying many mixed lesions the writer concludes that they can be classified and reported in

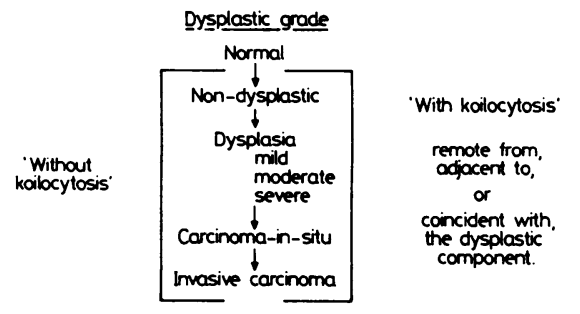

Fig. 5 Reporting cervical koilocytosis and dysplasia.

terms of two descriptors-(i) presence of koilocytosis and (ii) degree of apparent dysplasia. Assessment of the dysplastic component is made on the simplifying assumption that cells which look dysplastic are dysplastic. ${ }^{27}$ The writer's taxonomy of the koilodysplastic lesions is given in Fig. 5 and illustrated in Fig. 6. The method is simple to handle and the inclusion of the dysplastic grade in the nomenclature is valued by clinicians as a guide to treatment.

\section{COMPARISON OF DIFFERENT SYSTEMS}

Here the practices of two groups, Pilotti et $a^{28}$ and that of Meisels are correlated. The grade of dysplasia of the lesions named by each group has been determined from their published descriptions, photomicrographs and behaviour. Each named type can then be related to the histological dysplastic grades which form the central reference standard of Fig. 7. Equivalence of the different lesions can thus be established.

SYSTEM OF PILOTTI ET AL: DYSPLASIA BASED

The approach of Pilotti et al $^{28}$ resembles the writer's (Fig. 5) with minor differences. Condyloma acuminatum is regarded as distinct from flat condylomata. They acknowledge the widespread association between flat condyloma and the severe dysplasias which they refer to as "with koilocytosis" (Fig. 7). However, for the less dysplastic forms they use the terms "condyloma type 1" (without significant dysplasia) and "condyloma type 2" (with significant dysplasia, indistinguishable from mild). Such clear definition allows the two forms to be linked confidently to the scale of histological dysplasia (Fig. 7) by equivalence signs (=).

\section{MEISEL'S GROUP: THE ATYPICAL}

\section{CONDYLOMATA}

In 1981, Meisels et $a l^{29}$ added a dysplastic form to the family of flat and acuminate condylomata. They called it "atypical condyloma"- $a$ form of flat con- 


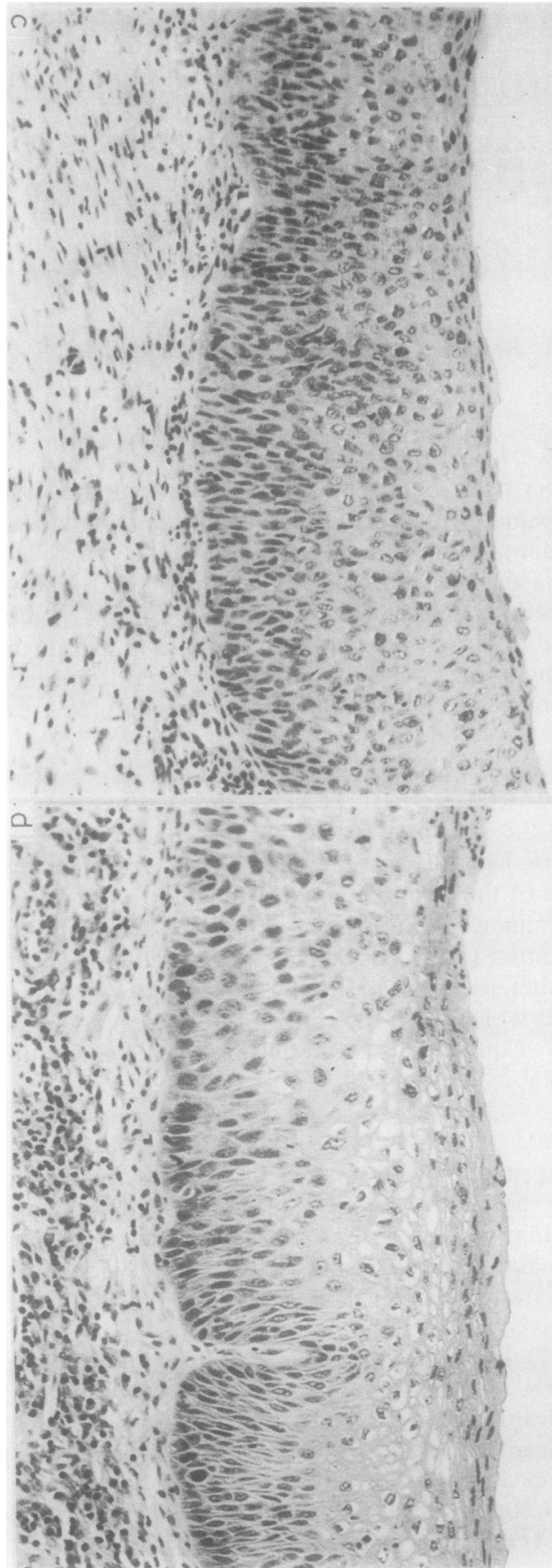

dyloma which so "mimicked dysplasia or carcinomain-situ" that misdiagnosis was likely. It "represented a more advanced step towards possible malignant transformation" whereas "other types of condyloma

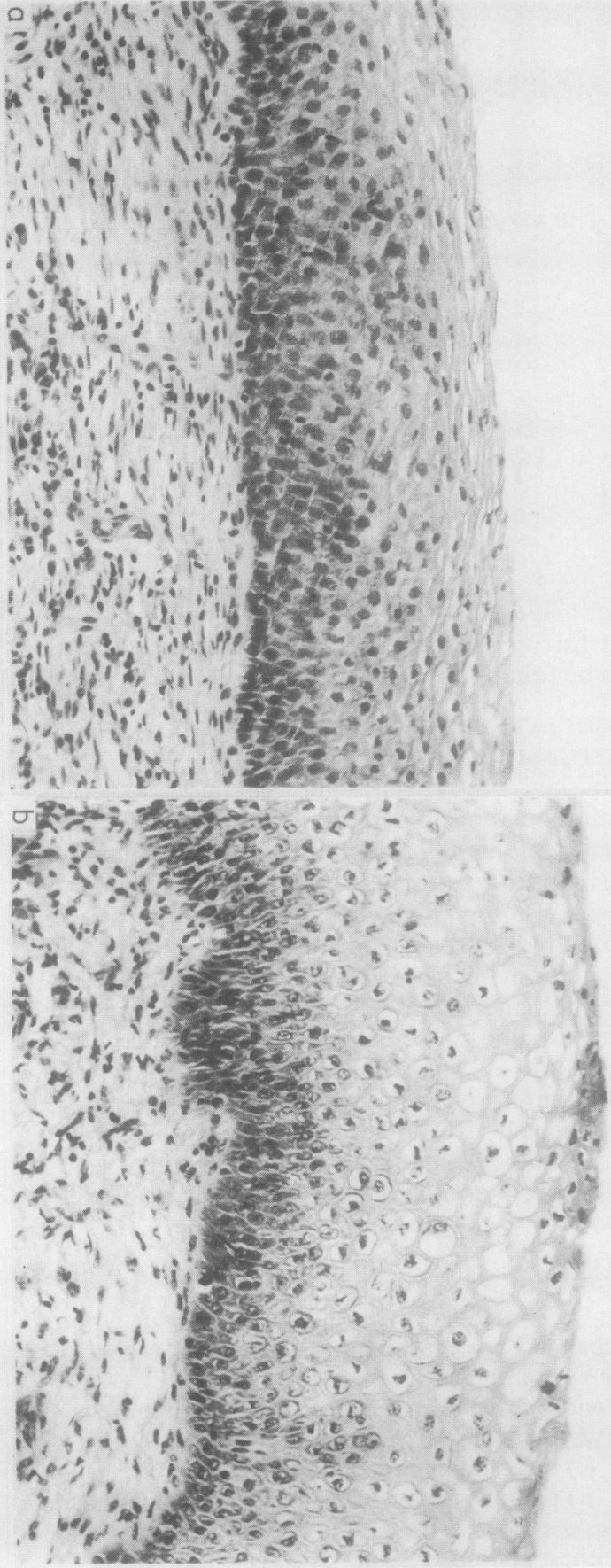

have a slower and smaller progression." Meisels et al regarded "atypical condyloma" as an entity with distinctive behavioural and morphological characteristics. Morphologically, it consists of a koilocytic 

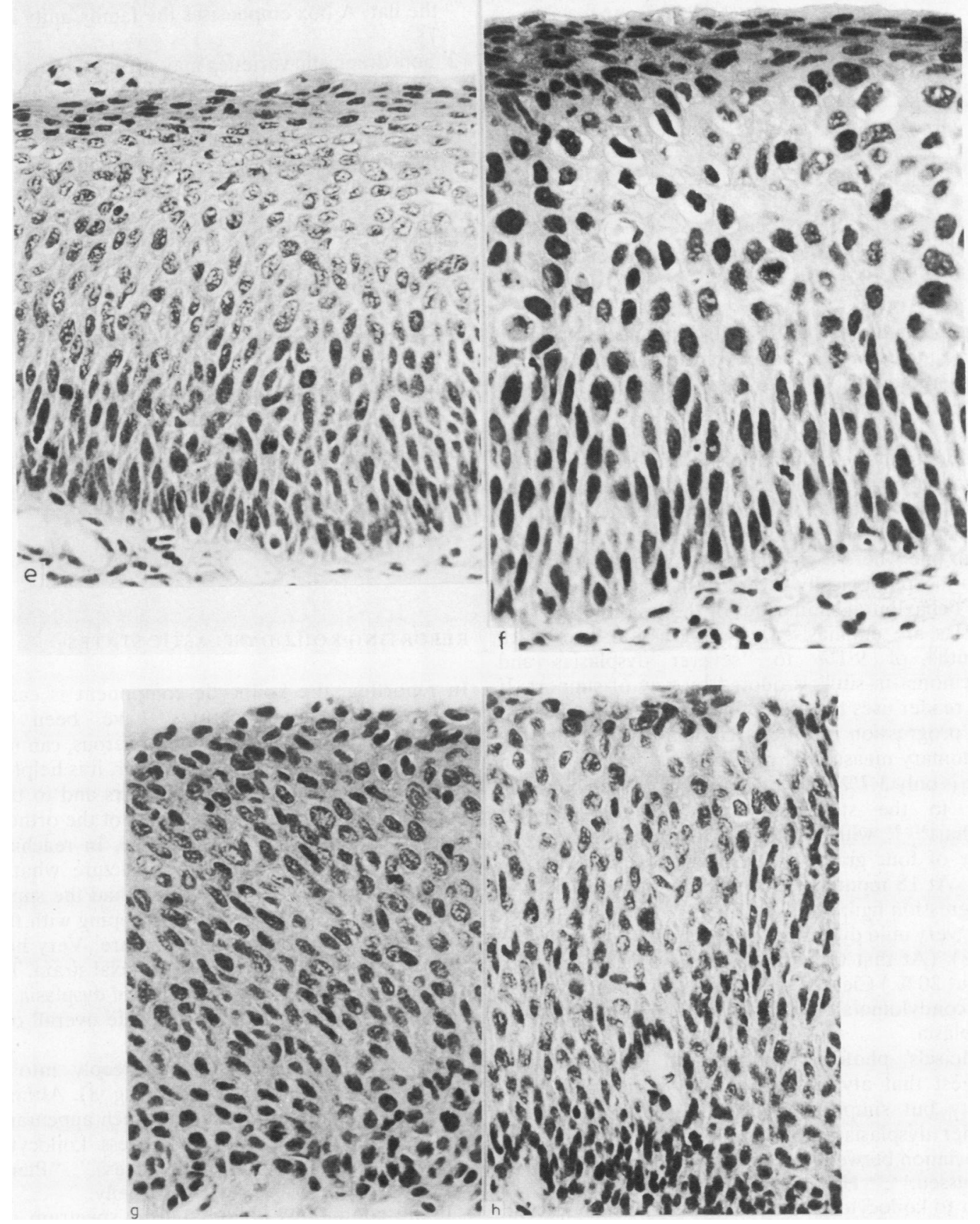

Fig. $6 \mathrm{a}-\mathrm{h}$ Paired examples of dysplasia in the absence and presence of koilocytosis. Note that as the grade of dysplasia and cellularity of the lesions increases, koilocytes diminish in number and in width of halo. Haematoxylin and eosin: (a) typical mild dysplasia $\times 160$; (b) mild dysplasia with koilocytosis $\times 160$; (c) typical moderate dysplasia $\times 160$; (d) moderate dysplasia with koilocytosis $\times 160$; (e) severe dysplasia (distinguished from carcinoma-in-situ by surface stratification) $\times 320 ;(f)$ severe dysplasia with koilocytosis $\times 320 ;(\mathrm{g})$ carcinoma-in-situ (distinguished from severe dysplasia by absence of surface stratification) $\times 320$; (h) carcinoma-in-situ with superficial koilocytosis $\times 320$. 


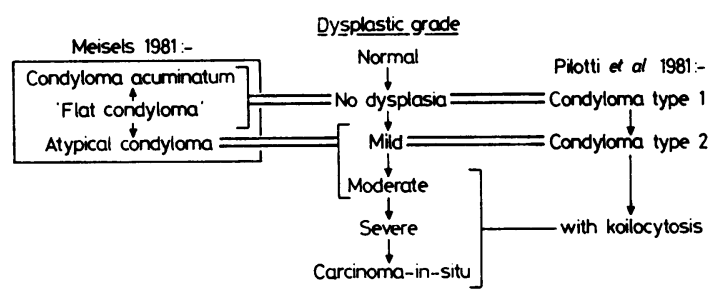

Fig. 7 Taxonomy of koilocytosis and dysplasia.

upper strata, with, in the mid-zone, nuclear aberrations including "smudged chromatin" and multinucleation attributed to viral infection. The deep zone is described as "containing almost normal cells" and its regularity is stressed. ${ }^{30}$ However, the normality of the cells in Meisels' Figs. 11, 12 and 13 is unconvincing: they are indistinguishable from the basal population of a mild or moderate dysplasia. Towards the end of the article the mood changes from one where a viral lesion may be misdiagnosed as a morphologically severe dysplasia to one where the behavioural similarities of the lesion to the dysplasias are emphasised. A progression rate at 18 months of $9.1 \%$ to "severer dysplasias and carcinoma-in-situ" is quoted by way of support. If the reader uses the data of Meisels $e t$ al to calculate the progression rate to carcinoma-in-situ only (the customary measure of progression) the progression rate is only $3.7 \%$. The calculated figure can be referred to the statistical curves of Barron and Richart $^{31-33}$ which estimate the progression with time of four grades of dysplasia to carcinoma-insitu. At 18 months after diagnosis of dysplasia, the progression figures closest to $3.7 \%$ lie on the curves for "very mild dysplasia" $(5 \%)$ and "mild dysplasia" $(6 \%)$. (At that time "moderate dysplasia" reaches about $20 \%$.) Clearly, the progression rate of "atypical condylomata" is less than that of the mildest dysplasia.

Meisels' photomicrographs and the calculation suggest that atypical condyloma is not a distinct entity but simply koilocytosis accompanying the milder dysplasias. This possibility, along with the association between koilocytosis and dysplasia is not discussed. ${ }^{1829}$ However, two later reviews ${ }^{2430}$ do refer to koilocytosis accompanying all the dysplastic grades, yet a dysplasia-based taxonomy is not suggested in preference to "atypical condyloma" which remains the sole, named, dysplastic condyloma in the taxonomy of Meisels' group. In conclusion (see also Fig. 7) Meisels' group consider that:

1 the condylomata are a family ${ }^{182930}$ and the acuminate and atypical forms are derivatives of the flat. A box emphasises the family unity in Fig 7 ;

2 non-dysplastic varieties may progress via atypical condyloma to a variable degree of dysplasia. ${ }^{8}$

The writer views the status of atypical condyloma as debatable and considers that:

1 its equivalent dysplasia is "mild to moderate" histologically (Fig. 7), and "very mild" behaviourally;

2 it lacks the secure diagnostic features, and hence the ease of definition of a strong entity. Some signs-for example, "smudged chromatin" 29 are hard to recognise and to distinguish from artefact. The regularity of the basal layer is not convincing in the illustrations; $;^{29} 30$

3 it does not occupy a constant dysplastic grade;

4 the term does not convey the prognostic information sought by clinicians;

5 in view of the ease of use of the dysplasia-based taxonomies, "atypical condyloma" could be abandoned.

\section{REPORTING KOILODYSPLASTIC STATES}

In reporting, the koilocytic component is easy to recognise and its features have been well described. ${ }^{30}{ }^{34}$ Koilocytes, when numerous, can make dysplasia difficult to grade. However, it is helpful to concentrate on the deeper cell layers and to try to assess their dysplasia using as many of the orthodox criteria $^{35}$ as may still be applicable. In reaching a conclusion it can be helpful to picture what the epithelium might have looked like had the superficial cells been of a type more in keeping with those beneath, and not of koilocytic nature. Very heavy koilocytosis may obscure the superficial strata. Then a search for non-koilocytic patches of dysplasia may supply enough information for a safe overall opinion.

Dense koilocytosis extending deeply into the epithelium is occasionally found (Fig. 8). Although all koilocytes are destined to die, such appearances are best reported as "full thickness koilocytosis with dysplasia impossible to assess." "Plenary koilocytosis" describes the state briefly.

If the continuous koilodysplastic spectrum does have a region sufficiently defined to merit the status of an entity then it is surely "plenary koilocytosis," characterised by its unmistakable appearance and its failure to match any of the recognised grades of dysplasia. ${ }^{35}$ Always patient safety is paramount and cases of doubt and difficulty in grading should be so described and suitable surveillance carried out. 




Fig. 8 Full thickness (plenary) koilocytosis. Halo formation in different degrees affects almost every cellular layer and the rules of dysplastic grading cannot be applied. Haemalum and eosin $\times 320$.

\section{NOMENCLATURE OF FLAT KOILOCYTOSIS}

\section{STATES}

The nomenclature of the "flat" lesions of wart virus in the cervix is both diverse and confusing:

Wart virus infections

Non-condylomatous wart virus infections (NCWVI).

Flat wart virus infections (FWVI).

\section{Condylomata}

Flat condylomata.

Condylomata (not further specified).

\section{Koilocytosis}

Non-condylomatous koilocytosis.

Flat koilocytosis.

The variety of names has the advantage of choice and each discipline can select the most appropriate. The following criticisms and preferences reflect the needs of the histopathologist.

Terms using the key-phrase "wart virus infection" Although potentially very accurate "wart virus infection" suffers from the weakness that histologically it may not be strictly justifiable unless the virus has been demonstrated in the lesions by electron microscopy or by immunological tracers. The names are also long and cumbersome but they are usefully inclusive.

Terms using the key-word "condyloma"

The propriety of the term "condyloma" for the exophytic condyloma acuminatum has been noted already, and terms which apply "condyloma" to the flat lesions are hence the most confusing. Although "flat condyloma" appears frequently in the present work it is used merely to ensure uniformity between original articles and their quotation.

"Flat condyloma" abuses the correct use of "condyloma" and is contradictory. "Flat koilocytosis" is more appropriate.

"Condyloma" (not further specified) is a source of great confusion in publications. It can be found used for "wart virus infections," "koilocytosis," "flat condyloma" (its commonest use) and also for "condyloma acuminatum." Usually its meaning can be attributed only by conjecture from the context or its illustrations. In the most extreme abuses of "condyloma" the expression can even change its meaning within a publication. Thus "condyloma" may be used throughout an article for "flat koilocytosis" but, occasionally, for "condyloma acuminatum" and the reader must detect and confirm the changed meaning from the context. In another instance, after frequent use of "condyloma" for "flat koilocytosis," a need arose to refer briefly to "condyloma acuminatum." The problem was solved by calling it "papillomatous condyloma" - the abuse of "condyloma" leading to another undesirable term.

Terms using "koilocytosis" as a key word

It is helpful to incorporate the main diagnostic feature of the infection. Koilocytosis, meaning koilocytes scattered singly or in clusters can express the intermingling of infected and dysplastic cells much better than condyloma-a topographically entire lesion where superimposition on other lesions becomes awkward.

For the flat wart virus lesions, "noncondylomatous koilocytosis" is accurate but it is lengthy, and involves negation. "Flat koilocytosis" is accurate, brief, positive and in the writer's opinion the most appropriate term for "flat condylomata" or "flat wart virus infections" of the cervix.

Histopathology would benefit from adopting "koilocytosis" as the primary identifying and taxonomic criterion of the wart virus lesions, with a secondary division by topography-"condylomatous" or "flat":

\section{Koilocytic cervical states}

II (a) Condylomatous koilocytosis ie condyloma acuminatum condyloma (abbreviation for condyloma acuminatum only).

(b) Flat koilocytosis All non-condylomatous forms. 
Note that "condylomatous koilocytosis" is taxonomic rather than nomenclatural-a way of classifying the state, thinking of it, and contrasting it with the "flat" form. It is not suggested as an additional synonym for condyloma acuminatum.

Definition and nomenclature is more than usually important for both the human ${ }^{36}$ and bovine ${ }^{20}$ lesions of wart virus because of their strain-specificity. Since virus strain identification depends on painstaking, skilled and expensive expertise in nucleic acid cloning and hybridisation, ${ }^{2037} 38$ it is imperative that it is not applied to badly-defined lesions misidentified by careless nomenclature.

I am grateful to Dr GS Smart and Dr JRB Livingstone for biopsies from the Colposcopy Clinic, the Royal Infirmary of Edinburgh, and to Dr Sybil McNair, Cytologist, Department of Pathology and Dr Mary Norval, Virologist, Department of Bacteriology, the University of Edinburgh, for helpful discussions.

\section{References}

' Meisels A, Fortin R. Condylomatous lesions of the cervix and vagina. I. Cytologic patterns. Acta Cytol 1976;20:505-9.

${ }^{2}$ Papanicolaou GN. The sexual cycle in the human female as revealed by vaginal smears. Am J Anat 1933;52:519-637.

${ }^{3}$ Ayre JE. The vaginal smear. 'Precancer' cell studies using a modified technique. Am J Obstet Gynecol 1949;58:1205-19.

${ }^{4}$ Koss LG, Durfee GR. Unusual patterns of squamous epithelium of the uterine cervix. Cytological and pathologic study of koilocytotic atypia. Ann N Y Acad Sci 1956;63:1245-61.

${ }^{5}$ Papanicolaou GN. Atlas of exfoliative cytology. Cambridge, Mass: Harvard, 1954: supplement 1960.

${ }^{6}$ Naib ZN, Masukawa N. Identification of condyloma acuminatum cells in routine vaginal smears. Obstet Gynecol 1961;18:735-

${ }^{7}$ Dunn AEG, Ogilvie MM. Intranuclear virus particles in human genital wart tissue. Observations on the ultrastructure of the epidermal layer. J Ultrastruct Res 1968;22:282-95.

${ }^{8}$ Meisels A, Fortin R, Roy M. Condylomatous lesions of the cervix. II. Cytologic, colposcopic and histopathologic study. Acta Cytol 1977;21:379-90.

${ }^{9}$ Reid R, Laverty CR, Coppleson M, Isarangkul W, Hills E. Noncondylomatous cervical wart virus infection. Obstet Gynecol 1980;55:476-83.

${ }^{10}$ Gissman L, de Villiers E-M, zur Hausen H. Analysis of human genital warts (condyloma acuminata) and other genital tumours for HPV6-DNA. Int J Cancer 1982;29:143-6.

"Della Torre G, Pilotti S, de Palo G, Rilke F. Viral particles in cervical condylomatous lesions. Tumori 1978;64:549-53.

${ }^{12}$ Casas-Cordero M, Morin C, Roy M, Fortier M, Meisels A. Origin of the koilocyte in condylomata of the human cervix. Ultrastructural study. Acta Cytol 1981;25:383-92.

${ }^{13}$ Grussendorf E-I, zur Hausen H. Localisation of viral DNAreplication in sections of human warts by nucleic acid hybridisation with complementary RNA of human papilloma virus type 1. Arch Dermatol Res 1979;264:55-63.

14 Koss LG. Diagnostic cytology and its histopathologic bases. 3rd ed. Philadelphia, Toronto: Lippincott, 1979:278 and 345 .

is Ayre JE. Role of the halo cell in cervical cancerigenesis. A virus manifestation in premalignancy? Obstet Gynecol 1960;15: 481-91.
${ }^{16}$ Jarrett A. Physiology and pathophysiology of the skin. London, New York: Academic Press, 1973: chapter 3.

${ }^{17}$ Burgos MH, Roig de la Vargas-Linares. In: Hafez ESC, Evans TN, eds. The human vagina. Amsterdam: Elsevier-North Holland Biomedical Press, 1978: chapter 5.

${ }^{18}$ Dulbecco R, Ginsberg HS. In: Davis BD, Dulbecco, R, Eisin HN, Ginsberg HS, eds. Microbiology. 3rd ed. Philadelphia: Harper and Row (Lippincott), 1980: chapter 66, 1232-41.

19 Ruiter M, von Mullem PJ. Further histological investigations on malignant degeneration of cutaneous lesions in epidermodysplasia verruciformis. Acta Derm Venereol (Stockh) 1970;50: 205-11.

${ }^{20}$ Jarrett WFH. Papilloma viruses and cancer. In: Anthony PP, MacSween RNM, eds. Recent advances in histopathology II. Edinburgh: Churchill Livingstone, 1981:35-48.

${ }^{21}$ Dawson DF, Duckworth JK, Bernhardt H, Young JM. Giant condyloma and verrucous carcinoma of the genital area. Arch Pathol 1965;79:225-31.

${ }^{22}$ Gardner HL, Kaufman RH. Condylomata acuminata. Clin $\mathrm{Ob}$ stet Gynecol 1965;8:938-45.

${ }^{23}$ Kovi J, Tillman RL, Lee SM. Malignant transformation of condyloma acuminatum. Am J Clin Pathol 1974;61:702-10.

${ }^{24}$ Meisels A, Morin C. Human papillomavirus and cancer of the uterine cervix. Gynecol Oncol 1981;12:S111-S123.

${ }^{25}$ Komorowsky RA, Clowry LJ. Koilocytotic atypia of the cervix. Obstet Gynecol 1976;47:540-4.

${ }^{26}$ Syrjanen KJ. Morphologic survey of the condylomatous lesions in dysplastic and neoplastic epithelium of the uterine cervix. Arch Gynecol 1980;227:153-61.

${ }^{27}$ Fletcher S, Norval M. On the nature of the deep cellular disturbances in papilloma virus infection of the squamous cervical epithelium. J Clin Pathol (submitted for publication April 1983).

${ }^{28}$ Pilotti S, Filke F, de Palo G, Della Torre G, Alasio L. Condylomata of the uterine cervix and koilocytosis of cervical intraepithelial neoplasia. J Clin Pathol 1981;34:532-41.

${ }^{29}$ Meisels A, Roy M, Fortier M, et al. Human papilloma virus infection of the cervix. The atypical condyloma. Acta Cytol 1981;25:7-16.

${ }^{30}$ Meisels A, Morin C, Casas-Cordera M. Human papilloma virus infection of the uterine cervix. Int J Gynecol Pathol 1982;1:75-94.

${ }^{31}$ Barron BA, Richart RM. A statistical model of the natural history of cervical carcinoma based on a prospective study of 557 cases. J Natl Cancer Inst 1968;41:1343-58.

${ }^{32}$ Barron BA, Richart RM. Statistical model of the natural history of cervical carcinoma. II. Estimates of the transition time from dysplasia to carcinoma-in-situ. J Natl Cancer Inst 1970; 45:1025-30.

${ }^{33}$ Richart RM. Natural history of cervical intraepithelial neoplasia. Clin Obstet Gynecol 1967;10:748-84.

${ }^{34}$ Recher L, Srebnik E. Histopathologic features of koilocytotic atypia. A detailed description. Acta Cytol 1981;25:377-82.

${ }^{35}$ Govan ADT, Haines RM, Langley FA, Taylor CW, Woodcock AS. The history and cytology of changes in the epithelium of the cervix uteri. J Clin Pathol 1969;22:383-95.

${ }^{36}$ Bunney MH. Viral warts: their biology and treatment. Oxford: Oxford University Press, 1982.

${ }^{37}$ Campo MS, Moar MH, Jarrett WFH, Laird HM. A new papilloma-virus associated with alimentary cancer in cattle. Nature 1980;286:180-2.

${ }^{36}$ Jarrett WFH, Campo MS, et al. Papilloma viruses in benign and malignant tumours of cattle. In: Essex M, Todaro G, zur Hausen $\mathrm{H}$, eds. Viruses in naturally occurring cancers. New York: Cold Spring Harbor Laboratory, 1980:1043-428.

Requests for reprints to: Dr S Fletcher, Department of Pathology, University Medical School, Teviot Place, Edinburgh EH8 9AG, Scotland. 